\title{
O QUE SE DISCUTE SOBRE INOVAÇÃo NO SETOR PÚBLICO BRASILEIRO: ANÁLISE DO PERÍODO ENTRE 2000 (PÓS LRF) E 2014
}

WHAT IS BEING DISCUSSED ON INNOVATION IN PUBLIC SECTOR IN BRAZIL: ANAL YSIS OF THE PERIOD BETWEEN 2000 (AFTER LRF) AND 2014

\author{
Andréia Neiva Oliveira ${ }^{1}$ \\ Alexandre de Freitas Carneiro ${ }^{2}$ \\ Ione Grace do Nascimento Cidade-Konzen ${ }^{3}$ \\ José Moreira da Silva Neto ${ }^{4}$
}

\begin{abstract}
RESUMO
Considerada um marco histórico legal no país, a Lei de Responsabilidade Fiscal (LRF) provoca maior rigor no controle, responsabilidade e transparência da gestão pública, o que torna imperativo novas práticas inovadoras. $O$ artigo tem por objetivo fazer o levantamento das discussões sobre inovação no setor público brasileiro após a LRF. A pesquisa é descritiva e o estudo documental, representado pela revisão de artigos disponíveis na base de dados eletrônicos da Scientific Electronic Library Online (Scielo) entre os anos de 2000, ano de vigência da LRF, até 2014. Categorizou-se os dados por temas que resultaram em nove. Dos 20 artigos encontrados, cinco abrangem inovação na saúde pública, tema predominante nas discussões. Os outros são referentes à gestão federal; às gestões estaduais, às gestões municipais; às melhores práticas; à educação; à pesquisa e tecnologia, propriedade intelectual e à estudos bibliométricos ou levantamento na literatura sobre o tema estudado. Há pouca discussão, de acordo com os artigos na base levantada, porém há mais estudos recentes com cinco artigos em 2014. Verificou-se pouco interesse em estudos sobre inovação pública com foco na educação.
\end{abstract}

Palavras-chave: Inovação; Setor público; Discussão de publicações. Lei de Responsabilidade Fiscal.

\begin{abstract}
Considered a historic milestone in the country, the Fiscal Responsibility Law $(\mathrm{FRL})$ causes greater rigor in the control, responsibility and transparency of public management, which makes it essential to new innovative practices. The article aims to survey the discussions on innovation in brazilian public sector after the FRL. The research is descriptive, and the study is documental. It is represented by the review of articles available on electronic database of the Scientific Electronic Library Online (Scielo) between the years 2000, year of the $\mathrm{FRL}$, until 2014. The data were categorized by themes, resulting in nine. From the 20 articles found, five of them cover innovation in public health, which is a predominant theme in the discussions. The others are related to the federal management; to state administrations, to the municipal administrations; to best

\footnotetext{
Bacharel em Ciências Contábeis pela Universidade Federal de Rondônia (UNIR). E-mail: bomjesusvhafinanceiro@gmail.com

${ }^{2}$ Mestre em Administração pela Universidade Federal de Rondônia (UNIR). Professor do Departamento de Ciências Contábeis da Universidade Federal de Rondônia (UNIR). E-mail: alexandrevha95@gmail.com

${ }^{3}$ Mestre em Administração pela Universidade Federal de Rondônia (UNIR). Professora de Administração da Faculdade Integrada Aparício Carvalho (FIMCA). E-mail: ionegrace@gmail.com

4 Doutor em Engenharia de Produção pela Universidade Federal de Santa Catarina (UFSC). Professor do Departamento de Ciências Contábeis da Universidade Federal de Rondônia (UNIR).
} 
practices; to the education; to research and technology, to intellectual property and to bibliometric study or survey of the literature about the subject studied. There is little discussion, according to the articles of the survey base, but there are recent studies with five articles in 2014. It was found little interest in studies on public innovation focusing on education.

Keywords: Innovation; Public Sector; Discussion of publications. Fiscal Responsibility Law.

\section{INTRODUÇÃO}

Nos últimos anos a gestão pública passou por grandes mudanças. Muitas dessas mudanças impulsionaram a elaboração, em 4 de maio de 2000, da Lei de Responsabilidade Fiscal (LRF), que determina diretrizes orçamentárias tanto para as três esferas dos poderes (Legislativo, Executivo e Judiciário) quanto para as esferas governamentais (União, Estados, Distrito Federal e Municípios).

A LRF é considerada um marco na política e gestão pública brasileira visto que, por intermédio dela, os governantes se atentaram em obedecer às normas que regem os gastos públicos e a prestação de contas desses gastos. Essa norma ainda determina que os cidadãos tenham acesso às contas públicas, podendo assim manifestar sua opinião sobre a gestão do patrimônio público. Essa lei exige maior rigor no controle financeiro, além da ênfase na administração do erário com maior responsabilidade.

Antes da LRF, discutia-se sobre um novo modelo de gestão pública: a nova gestão pública (New Public Management) ou Administração Pública Gerencial. De acordo com Matias-Pereira (2008) esse novo modelo de gestão pública teve início na Grã-Bretanha, com Margareth Thatcher, em 1979, e seguiu nos EUA com Reagan, em 1980. Mas no Brasil, com a reforma gerencial nos anos 1990, conforme Bresser Pereira (2000) constituiu-se todo um quadro teórico e uma prática administrativa, visando a modernização do Estado e a tornar sua administração mais eficiente, voltada para o cidadãocliente.

De acordo com Lima e Vargas (2010), os autores da literatura nacional sobre inovação no setor público apresentam interação restrita entre si e com os estudos sobre inovação em serviços e afirmam ainda que, possibilidades de pesquisas sobre inovações no setor público são amplas. Desse modo, surge a justificativa de uma pesquisa sobre o que se discute sobre inovação no setor público após um grande marco na Administração Pública, que é a LRF.

É nesse cenário que emerge a questão norteadora para o presente estudo: o que está sendo discutido sobre inovação no setor público? Sendo assim, o presente artigo tem como objetivo fazer o levantamento das discussões do tema inovação no setor público brasileiro após a vigência da LRF, ou seja, em 2000, até 2014.

O estudo está dividido em cinco seções, incluindo a introdução. A segunda apresenta o referencial teórico sobre Gestão da Inovação e Inovação 
no setor público. Na terceira apresentam-se os procedimentos metodológicos, e na quarta a apresentação e a discussão dos resultados e a síntese. A última descreve as conclusões e sugestões para novas pesquisas.

\section{REFERENCIAL TEÓRICO}

\subsection{Gestão da Inovação}

O tema da inovação tem atraído o interesse de pesquisadores, acadêmicos e empresários. Na última década, a inovação passou a ser reconhecida como um fator essencial para a competitividade das organizações. Segundo Dias (2014), ao se tratar de inovação econômica, faz-se necessário atentar para os trabalhos de Joseph Alois Schumpeter em 1997. Para o autor, a inovação é o motor do crescimento econômico e o fator empresarial é o elemento chave no processo de geração de inovações. Dias aponta a incerteza como obstáculo para o investimento em inovação, destacando que o tamanho empresarial e a concentração do setor são fatores que ajudam a reduzi-la. De acordo com esse autor as empresas grandes são mais inovadoras do que as pequenas e as barreiras existentes na implantação de algo novo no mercado dificultam a inovação no setor.

Tidd, Bessant e Pavitt (2008) discutem o tema central da teoria original de Schumpeter sobre a Inovação. Eles afirmam que Schumpeter acreditava que se deveria envolver um processo de "destruição criativa", e fazem alusão às descontinuidades ocasionais e o surgimento de condições do tipo "faça algo diferente". Os autores descrevem os tipos de inovações, os "4 Ps" da inovação. São eles: Inovação de produto - mudanças nas coisas (produtos/serviços) que uma empresa oferece, Inovação de processo - mudanças na forma em que produtos/serviços são criados e entregues, Inovação de posição - mudanças no contexto em que produtos/serviços são introduzidos e Inovação de paradigma - mudanças nos modelos mentais subjacentes que orientam o que a empresa faz.

Para Dias (2014), inovação consiste na introdução com êxito no mercado de produtos e serviços, entre outros que não existam ou que apresentam melhorias marcantes. Tal processo pode resultar de novos desenvolvimentos, combinações de tecnologia ou de outros conhecimentos adquiridos pela empresa. A inovação tem como objetivo gerar um impacto positivo no mercado através do desenvolvimento de novos produtos e serviços e mudanças nos aspectos gerais da empresa (DIAS, 2014).

Ainda segundo Dias, a gestão inovadora pode definir-se como organização e controle de recursos disponíveis que visam o aumento da criação de novos produtos, processos, conhecimentos e sua aplicação na estrutura da empresa. Sua principal base é o conhecimento. Assumir riscos, desenvolver espírito empreendedor, garantir apoio da alta direção, estabelecer sistemas de compensação, assimilar conhecimentos, experimentar, manter comunicação eficiente, apoiar a diversidade cultural e melhorar a capacidade de conter as interrupções associadas às mudanças são pontos fundamentais para a existência de um ambiente favorável à inovação (DIAS, 2014). 
Com as exigências dos consumidores, as empresas estão buscando inovar em seus produtos e serviços. É preciso inovar porque o consumidor mudou seu comportamento de compra, seu universo cresceu, ele tem mais informações à sua disposição, pode fazer comparações. Mas a empresa também se beneficia ao buscar inovação, porque isto permite que as empresas acessem novos conhecimentos, novos mercados, aumentem suas receitas, realizarem novas parcerias, podendo provocar um comportamento de fidelidade do seu cliente (BAUTZER, 2009).

No Quadro 1 são apresentadas as questões básicas de que as organizações almejam para alcançar a inovação. Devem levar em consideração os fatores ambientais que contribuem para a asfixia da inovação para eliminá-los.

\section{Quadro 1: Questões básicas para inovação e fatores que asfixiam.}

\begin{tabular}{|l|l|}
\hline $\begin{array}{l}\text { Questões básicas para alcançar a } \\
\text { inovação: }\end{array}$ & $\begin{array}{l}\text { Fatores ambientais que asfixiam a } \\
\text { inovação: }\end{array}$ \\
\hline Promover a criatividade dentro da equipe. & $\begin{array}{l}\text { Falta de entrosamento por conta de escala } \\
\text { hierárquica. }\end{array}$ \\
\hline Organizar a inovação, passo a passo. & Má comunicação entre os colaboradores. \\
\hline $\begin{array}{l}\text { Reinventar a gestão para direcioná-la para a } \\
\text { inovação. }\end{array}$ & Ordens de cima para baixo. \\
\hline $\begin{array}{l}\text { Tudo que é novo assusta, deve saber } \\
\text { administrar as mudanças. }\end{array}$ & Falta de criatividade nas mudanças. \\
\hline $\begin{array}{l}\text { Administrar e compartilhar os conhecimentos } \\
\text { mútuos. }\end{array}$ & $\begin{array}{l}\text { Não dar atenção aos conhecimentos dos } \\
\text { colaboradores internos. }\end{array}$ \\
\hline $\begin{array}{l}\text { Gerenciar a diversidade entre a equipe de } \\
\text { forma eficaz e responsável. }\end{array}$ & Atividade inovadora sem foco. \\
\hline & $\begin{array}{l}\text { Práticas contábeis que não apoiam a } \\
\text { inovação. }\end{array}$ \\
\hline
\end{tabular}

Fonte: Dias (2014, p. 76-77).

Como se nota, para inovar, a criatividade é uma questão básica e sua falta a asfixia. A organização deve assumir os riscos e desafios, para isso, são necessários gestores capazes de converter ideias em decisões concretizadas, que funcionem com êxito tornando possível a inovação.

O Quadro 2 mostra uma tipologia básica e de acordo com a natureza de inovação classificada em cinco modos principais. Todos os tipos de inovação necessitam de disposição para mudança. Por exemplo, a inovação em serviços, só acontece por meio da habilitação e capacitação dos funcionários da empresa por meio de treinamento para conceber ou programar a inovação em serviço.

\section{Quadro 2: Tipologias de Inovação.}

Básica 


\begin{tabular}{|l|l|}
\hline Inovação do produto & $\begin{array}{l}\text { Lançamento de um novo produto ou serviço, bem como } \\
\text { alguma melhoria atribuída a algo já existente. }\end{array}$ \\
\hline Inovação de processo & $\begin{array}{l}\text { Colocar em prática um método de produção ou distribuição } \\
\text { novo ou com melhorias. }\end{array}$ \\
\hline Inovação de marketing & $\begin{array}{l}\text { Aplicação de novas técnicas de apresentação do novo } \\
\text { produto ou de suas qualidades ao público final. }\end{array}$ \\
\hline Inovação organizacional & $\begin{array}{l}\text { Uso de novas técnicas aplicadas às práticas de negócio no } \\
\text { ambiente interno e nas relações externas da empresa. }\end{array}$ \\
\hline Inovação nos mercados & $\begin{array}{l}\text { Uso de novas matérias-primas ou melhorias que resultem na } \\
\text { rentabilidade da produção e a entrada de novos mercados. }\end{array}$ \\
\hline De acordo com a natureza & \multicolumn{2}{|l|}{$\begin{array}{l}\text { Criação de novas ferramentas de auxílio a novos processos } \\
\text { produtivos. }\end{array}$} \\
\hline Inovações tecnológicas & $\begin{array}{l}\text { Promoção, distribuição e comercialização de produtos e } \\
\text { serviços. }\end{array}$ \\
\hline Inovações comerciais & $\begin{array}{l}\text { Direcionadas à aplicação de tarefas organizacionais para } \\
\text { melhor aproveitamento de recursos humanos. }\end{array}$ \\
\hline Inovações organizacionais & Modificações para melhorias nas aplicações financeiras. \\
\hline Inovações financeiras & Atualizam ou melhoram a prestação de um bem ou serviço. \\
\hline Inovações em serviços & \\
\hline Fonte: Dias (2014 p. 86) &
\end{tabular}

Fonte: Dias (2014, p. 86).

Segundo Daft (2014), novos produtos e serviços são um caso especial de inovação porque são usados por clientes de fora da organização. Como grande parte dos órgãos públicos prestam serviços à sociedade, inová-los é imprescindível, a inovação é caminho sem volta (BAUTZER, 2009). Desse modo, é relevante entender a explicação de Daft (2014) sobre a diferença entre mudança organizacional e inovação organizacional, e ele ensina que:

"Mudança organizacional é considerada a adoção de uma nova ideia ou comportamento por uma organização. A inovação organizacional é a adoção de uma ideia ou comportamento que é novo para o setor, mercado ou ambiente geral da organização" (p. 420).

Büttenbender et al. (2007) buscou de maneira inovadora e diferenciada relacionar os processos de aprendizagem e a acumulação de competências tecnológicas com o aprimoramento do desempenho técnico e econômico na indústria metal-mecânica, fabricante de máquinas agrícolas. Para esses autores, a gestão da inovação, a aquisição e socialização de novos conhecimentos e a acumulação de competências tecnológicas impelem papel importante e influenciam positivamente o aprimoramento da performance de produção. Finalizam citando a importância do estímulo às políticas públicas que incentivem a maior autonomia na produção, exploração de tecnologias e fomento aos investimentos nacionais em Pesquisa e Desenvolvimento (P\&D), os quais são altamente estratégicos para a aceleração tanto da acumulação das competências tecnológicas, quanto no aprimoramento da performance e a promoção do desenvolvimento. 
Andrade Júnior e Ceranto (2013) ao fazer um mapeamento da produção científica brasileira sobre Gestão da Tecnologia e da Inovação (GTI), no período 2001-2011, mencionaram três aspectos de grande importância. Primeiramente, que diante do tamanho do país, em termos de extensão territorial ou número de habitantes, um pequeno número de artigos publicados sobre o assunto GTI: 46,18 artigos por ano ou 0,9055 artigos por periódico por ano. Em segundo lugar, que a produção científica brasileira sobre GTI encontra-se fortemente concentrada em determinados estados e municípios. Os autores concluíram que se o estudo for levado em consideração pelos agentes do Sistema Nacional de Inovação Brasileiro, podem trazer contribuições significativas para o cenário tecnológico nacional. Desta maneira, sugere-se a necessidade de políticas governamentais para incentivar uma maior produção científica na área de GTI no país como um todo, sobretudo nas localidades nas quais esta ainda se mostra muito baixa.

\subsection{Inovação no Setor Público}

No setor público, segundo Campelo (2012), também há necessidade de modelos de gestão que conduzam à excelência. Esse autor descreve os fundamentos ao elaborar um modelo conceitual de excelência em gestão pública. Cultura de Inovação é um deles, e conforme explica, é a "Implementação de novas ideias aperfeiçoando os produtos e serviços da organização. A inovação deve fazer parte da cultura da organização" (p. 215).

Ribeiro e Farias (2012, p. 54) citam o conceito de inovação aplicado ao setor público, do Canada School of Public Service, que considera inovação como "a geração e a aplicação criativa de novas ideias que produzam uma melhoria significativa em um produto, serviço, atividade, iniciativa, estrutura, programa ou política". Ribeiro e Farias citam como exemplo, no Brasil, de modalidade inovadora, o pregão eletrônico. Essa modalidade de licitação requereu a decisão de "demolir a velha tradição e criar uma nova", conforme a teoria de Schumpeter, ao abandonar práticas "analógicas" tradicionais nas modalidades licitatórias previstas na lei 8.666/93.

Outro elemento inovador na gestão pública, na concepção de Girardello e Maia (2012, p. 65), é "o planejamento estratégico com definição clara dos objetivos, escolha dos projetos estruturadores, definição de metas quantitativas, acompanhamento, avaliação e cobrança". Nessa linha de concepção, Pascarelli Filho (2011) advoga que o pensamento e o planejamento estratégico é ponto indispensável na profissionalização, e uma função do novo administrador público.

Zani e Spinelli (2010) objetivaram apresentar os resultados de uma pesquisa de campo que buscou identificar a influência do modelo de gestão pública privilegiado no Espírito Santo sobre as inovações introduzidas no âmbito da Administração Pública Estadual. A observação das transformações no Governo do Estado do Espírito Santo indica uma inclinação às propostas de reforma gerencial. Também o Plano de Gestão para o Desenvolvimento e Inclusão Social, documento que institui a Política Pública de Gestão no Estado, corrobora a impressão de reforma gerencial quando trata das políticas de pessoal, da eficiência administrativa e do controle do gasto, de tecnologia, de inovação na gestão e de ética pública. 
Pressupondo o servidor público como o principal agente de transformação da gestão, Zani e Spinelli (2010) citam o Prêmio Inoves como instrumento da política de recursos humanos para fomentar os valores condizentes com o modelo de gestão privilegiado no Espírito Santo: empreendedorismo, resgate do valor do servidor público, envolvimento no processo de melhoria contínua da gestão. O foco no servidor como agente de mudança, pode favorecer a personificação dos projetos inovadores, ocasionando a apropriação individual destes ou ainda a transformação do Prêmio no objetivo último da inovação. Os autores concluíram que o papel de orientador das inovações públicas pretendido pelo governo estadual pode se transferir para as equipes, ficando aquele somente com a função de induzir as inovações.

Oliveira (2012) defende que os governos precisam objetivar a promoção da inovação, criatividade e empreendedorismo no serviço público, mas considera um desafio o desenvolvimento do espírito empreendedor e inovador, pois o ambiente do serviço público desestimula atitudes inovadoras dos servidores, e para tanto, deve-se criar um clima organizacional para vencer tal desafio.

Nesse mesmo pensamento o objetivo do estudo de Lima e Vargas (2010) foi situar a discussão atual sobre inovação no setor público no Brasil e contrastá-la com estudos sobre inovação em serviços, visando identificar oportunidades de pesquisa. Após análise, concluíram que os autores da literatura nacional sobre inovação no setor apresentam interação restrita entre si e com os estudos sobre inovação em serviços. De um lado, há artigos que se fundamentam nas escolas de administração pública e de outro os que se fundam na economia.

Para entender a inovação nos serviços públicos, é necessário aproximar essas duas correntes e agregar as contribuições dos estudos sobre inovação em serviços de forma a abarcar a complexidade e a diversidade do setor público. As possibilidades de pesquisa sobre inovações no setor público são amplas, considerando-se a pouca produção nacional na área. As contribuições mais evidentes que a literatura de inovação em serviços referem-se à representação do produto dos serviços em termos de vetores de características e competências, à abordagem convencional de avaliação dos serviços e à análise do processo de inovação pela Actor-Network Theory (LIMA; VARGAS, 2010).

Lima e Vargas (2012) também realizaram um estudo para situar as discussões sobre inovação no setor público em revistas internacionais visando identificar oportunidades de pesquisa. Eles concluíram que os artigos revelam uma visão da inovação como mudança imposta de cima para baixo e não como processo interativo e intrínseco à atividade pública. 


\section{PROCEDIMENTOS METODOLÓGICOS}

Ao caracterizar o estudo com base na estrutura delineada por Gil (2008) teve a seguinte configuração: (1) quanto à natureza, é uma pesquisa aplicada; (2) quanto aos objetivos descritiva e (3) quanto aos procedimentos, documental. A natureza da pesquisa enquadra-se como descritiva e o estudo documental é representado pela análise e categorização de artigos disponíveis na base de dados eletrônicos da Scientific Eletronic Library Online (Scielo), publicados entre 2000 e 2014, ou seja, a partir da vigência da Lei de Responsabilidade Fiscal (LRF), pois, esta é considerada um marco legal ou um "divisor de águas" na gestão pública responsável.

A coleta de dados foi realizada através da consulta na base de dados eletrônico da Scielo, por meio de busca refinada com a utilização das palavraschave: "inovação no setor público", "inovação na gestão pública", "inovação na administração pública". A busca, embora realizada pelo uso de palavras-chave, levou-se em consideração a discussão sobre o tema e não apenas a citação do termo. No Quadro 3 apresentam-se a caracterização e etapas resumidas da pesquisa.

\section{Quadro 3: Caracterização e etapas da pesquisa.}

\begin{tabular}{|l|l|}
\hline Caracterização/Etapas & \multicolumn{1}{|c|}{ Descrição } \\
\hline 1. Pergunta: & O que está sendo discutido sobre inovação no setor público? \\
\hline 2. Base de dados: & $\begin{array}{l}\text { Artigos disponíveis do meio digital de acesso livre e artigos } \\
\text { pertencentes à base da Scientific Eletronic Library Online (Scielo) } \\
\text { com publicação no período compreendido entre março de 2000 } \\
\text { até novembro de 2014. }\end{array}$ \\
\hline 3. Critérios de busca: & $\begin{array}{l}\text { Artigos que contenham a palavra “inovação no setor público", } \\
\text { "inovação na administração pública", "inovação na gestão } \\
\text { pública". }\end{array}$ \\
\hline $\begin{array}{l}\text { 4. Aplicação dos } \\
\text { critérios de busca e } \\
\text { possíveis exclusões: }\end{array}$ & $\begin{array}{l}\text { Artigos científicos que contemplem a discussão sobre inovação } \\
\text { no setor público. A análise documental foi realizada em 20 artigos } \\
\text { encontrados. }\end{array}$ \\
\hline $\begin{array}{l}\text { 5. Análise crítica dos } \\
\text { artigos: }\end{array}$ & $\begin{array}{l}\text { Optou-se pela realização de análise interpretativa com } \\
\text { categorizações temáticas. }\end{array}$ \\
\hline
\end{tabular}

Fonte: Elaboração própria com base no método de Silva, Mello e Torres (2013).

O procedimento metodológico utilizado é semelhante ao de Silva, Mello e Torres (2013) que tiveram como objetivo investigar como estão sendo discutidas as articulações entre gestão por competências e setor público.

$\mathrm{Na}$ análise documental procurou-se, pela leitura dos 20 artigos, obter 0 conteúdo, e de acordo com os objetivos de pesquisa de cada um, categorizar 
ou agrupar por temas. Resultaram, desse modo, nove temas e foram sintetizados no final da seção seguinte.

\section{4 . APRESENTAÇÃO E ANÁLISE DOS RESULTADOS}

As seções seguintes foram organizadas de modo a apresentar uma breve análise da produção científica, e após, analisar o conteúdo das discussões sobre o tema.

\subsection{Breve Análise da Produção Científica}

A Tabela 1 apresenta uma síntese de distribuição, analisada por periódicos que mais publicaram artigos relacionados ao tema.

Tabela 1: Distribuição dos artigos por periódicos.

\begin{tabular}{|l|c|c|}
\hline \multicolumn{1}{|c|}{ Periódico } & № & $\%$ \\
\hline Cadernos ENAPE & 2 & 10 \\
\hline Ciência e Saúde Coletiva & 3 & 15 \\
\hline Gestão e Regionalidade & 2 & 10 \\
\hline Revista Brasileira de Educação & 1 & 5 \\
\hline Revista da Administração Pública (R A P) & 8 & 40 \\
\hline Revista da Saúde Pública & 1 & 5 \\
\hline Revista de Administração de Empresa (R A E) & 1 & 5 \\
\hline Revista Sequência & 1 & 5 \\
\hline SP em Perspectiva & 1 & 5 \\
\hline Total & $\mathbf{2 0}$ & $\mathbf{1 0 0}$ \\
\hline
\end{tabular}

Fonte: Elaboração própria.

Verifica-se que houve maior publicação de artigos pela Revista de Administração Pública (RAP) que teve 8 dos 20 artigos encontrados, um total de 40\%. Em segundo lugar está a Ciência e Saúde Coletiva com 3 artigos, equivalente a 15\%, seguida de Cadernos ENAPE e Gestão e Regionalidade com 2, 10\%, e, por fim, a Revista Brasileira de Educação, a Revista de Saúde Pública, a Revista de Administração de Empresa, a Revista Sequencia e a SP em Perspectiva com 1 artigo, ou seja, 5\% cada.

A Tabela 2 na sequência traz uma distribuição anual dos artigos por periódicos. Dos anos analisados, 2014 teve o maior número totalizando 5 artigos. Em segundo lugar 2010 com 2 artigos, o restante foi distribuído entre os outros anos. Vale ressaltar que em 2004, 2007, 2008 e 2011 não houve publicações. Percebem-se mais publicações em períodos de eleições, nos anos 2002, 2006, 2010 e 2014. 
Tabela 2: Número de artigos por ano.

\begin{tabular}{|c|c|c|c|c|c|c|c|c|c|c|c|}
\hline Periódico & 2000 & 2001 & 2002 & 2003 & 2005 & 2006 & 2009 & 2010 & 2012 & 201 & 2014 \\
\hline Cadernos ENAPE & & & & 1 & & 1 & & & & & \\
\hline Ciência e Saúde Coletiva & 1 & 1 & 1 & & & & & & & & \\
\hline Gestão e Regionalidade & & & & & & 1 & & & & & \\
\hline $\begin{array}{l}\text { Revista Brasileira de } \\
\text { Educação }\end{array}$ & & & & & 1 & & & & & & \\
\hline Revista da Adm. Pública & & & & & & & 1 & 2 & . & & 3 \\
\hline Revista da Saúde Pública & & & & & & & & & 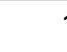 & & \\
\hline $\begin{array}{l}\text { Revista de Adm. de } \\
\text { Empresa }\end{array}$ & & & 1 & & & & & & & & \\
\hline Revista Sequencia & & & & & & & & & & & 1 \\
\hline SP em Perspectiva & & & & & & & & & & & 1 \\
\hline Total & 1 & 1 & 2 & 1 & 1 & 2 & 1 & 2 & 2 & 2 & 5 \\
\hline
\end{tabular}

Fonte: Elaboração própria.

$\mathrm{Na}$ seção seguinte apresenta-se o conteúdo das discussões sobre inovação no setor público representadas pelas publicações nacionais após a LRF até 2014.

\subsection{O Que se Discute Sobre Inovação no Setor Público}

Essa seção é descritiva e analisa os estudos revisados segundo seus objetivos, método e conclusões dos autores, e segue a ordem cronológica das publicações. Em seguida é elaborado um quadro-síntese.

O objetivo de Costa et al. (2000) em seu estudo analisou o processo de difusão da agenda da reforma no Estado, tomando como caso a área da Saúde nas regiões metropolitanas do Rio de Janeiro e São Paulo. Também examinou as principais inovações gerenciais e identificou as tendências de desenvolvimento. As organizações hospitalares estudadas mostraram ineficiência e baixo empenho na geração de benefícios públicos. Isso mostra que essas organizações estão diante de uma crise, o que estimula mudança de sua missão e exige uma nova interação com o Estado. Os autores concluíram que para o processo de inovação na gestão pública tenha êxito é necessário introduzir rotinas de avaliação que permitam apontar os parâmetros e indicar mudanças de curso.

Quadros et al. (2000) tinham por objetivo fazer um exercício de reflexão sobre o sistema de inovação paulista à luz da análise das informações sobre 0 sistema público de C\&T (Ciência e Tecnologia) no Estado de São Paulo e abordar os principais problemas das universidades e dos institutos de pesquisa, estaduais e federais. Uma das principais conclusões dos autores 
consistiu na identificação de um desequilíbrio no sistema de inovação paulista. Além disso, o déficit no balanço das importações e exportações de serviços tecnológicos e o tímido desempenho do Estado no patenteamento de inovações tecnológicas sugerem que a indústria paulista tem muita inovação e pouco conhecimento. O conhecimento científico e tecnológico acumulado pelo investimento em C\&T não tem se traduzido em capacitação tecnológica e de inovação no setor produtivo, porém a efetividade das políticas de C\&T e da inovação não depende apenas dos incentivos governamentais.

O trabalho realizado por Gerschman (2001) teve por objetivo analisar as inovações gerenciais que se produziram no setor da saúde no processo de descentralização da Política de Saúde. A autora, após mapeamento da situação do Sistema Único de Saúde (SUS), concluiu que em alguns municípios o tipo de inovação gerencial incorporada significa um avanço no processo de descentralização e implementação do SUS através de iniciativas da própria gestão municipal, enquanto em outros se observa a implantação de programas e experiências formuladas exclusivamente nos níveis federal/estadual que são incorporadas pela gestão municipal como uma maneira de injetar recursos externos no município. Quanto às indagações relativas às inovações gerenciais e de recursos humanos, quase a totalidade dos gestores menciona sua incorporação no sistema municipal de saúde. 0 tipo de inovação se refere, na maioria, à criação de gerências distritais e conselhos gestores de unidade com participação da comunidade. A autora também menciona as inovações na avaliação de desempenho, na formação de cooperativas médicas, terceirização e na introdução de cursos de Administração Hospitalar.

Baracchini (2002) objetivou discutir a inovação sob a perspectiva de um administrador público com a apresentação de um caso prático - premiado pelo Programa Gestão Pública e Cidadania. Segundo a autora os programas inovadores promovidos por governos municipais são parte das alterações do Estado e também nos processos de formulação e implementação das políticas públicas. Porém, há muito a ser feito para o avanço das políticas públicas e das gestões públicas no país no que se refere à inovação e ela acredita na necessidade de proposição de mudanças. Criado em 1996 o Programa Gestão Pública e Cidadania vem trabalhando de maneira ativa na identificação e disseminação de iniciativas inovadoras dos governos de estados e municípios brasileiros que melhoram a qualidade dos serviços públicos e contribuem para construção da cidadania.

Spink (2003) fala sobre o tema inovação a partir de respostas dos programas, projetos e atividades identificadas a esta questão, trazendo uma nova ótica à discussão entre inovação e melhores práticas. $O$ autor conclui que a inovação, voltando ao seu uso diário e cotidiano, é normalmente entendida como algo novo em relação ao anterior, nas respostas parece que as pessoas responsáveis pelos programas, projetos e atividades inscritos no ciclo de premiação do Programa Gestão Pública e Cidadania têm pouca dificuldade em reconhecer onde estão as mudanças.

Conde e Araújo-Jorge (2003) analisaram as diversas acepções do termo Inovação presentes na literatura. A partir da revisão da literatura sobre 
inovação e modelos de análise da inovação analisaram-se as concepções de inovação coletadas junto a gestores da Fiocruz. A revisão realizada permitiu evidenciar que, nas últimas décadas do século 20, a eficiência e efetividade dos sistemas de inovação foi o foco central de preocupação e estudos na maioria dos países. Os autores constataram que a complexidade dos processos envolvidos na geração da inovação, a dificuldade de identificação dos nexos causais entre ciência, tecnologia, economia e sociedade e a aceleração das mudanças do papel do conhecimento geraram, nesse período, uma grande propagação de modelos de análise e forçaram a revisão e atualização dos instrumentos internacionais de análise e mensuração das atividades de P\&D, ainda em andamento.

As atividades de inovação e as capacidades tecnológicas que se referem ao processo de acumulação de capacidades institucionais para adquirir, assimilar, incorporar, criar e utilizar conhecimentos, e que seriam os aspectos-chave para a análise e avaliação da inovação nos países em desenvolvimento, esteve praticamente ausente das concepções coletadas. Ainda, supõem, Conde e Araújo-Jorge (2003), que a falta de clareza e de harmonia dos gestores acerca das concepções a serem adotadas refletem uma absorção acrítica da perspectiva de inovação veiculadas pelas propostas governamentais. Eles acreditam que, para compatibilizar e articular as políticas de C\&T com os objetivos de igualdade, integralidade e universalidade da atenção à saúde vigentes no Brasil, é necessário pensar uma política de inovação que confira um novo estatuto à dimensão social na determinação da geração de inovação e que concilie os objetivos de inserção competitiva nos mercados globalizados com os objetivos de maior e melhor distribuição de seus resultados, direcionando esses resultados para necessidades ou problemas sociais mais abrangentes. Essa política terá de trabalhar com uma compreensão mais abrangente de inovação enfatizando o desenvolvimento de capacidades tecnológicas, promovendo estudos para o desenvolvimento de modelos de análise e de formulação de políticas setoriais, locais e regionais mais adequados às suas especificidades e revalorizar as trajetórias tecnológicas institucionais bem-sucedidas, como é o caso da Fiocruz.

Silva Júnior e Sguissardi (2005) expõem alguns elementos históricos, conceituais e de princípios, para um exame preliminar do anteprojeto de lei da educação superior, na versão de seis de dezembro de 2004, como parte e decorrência do processo de transformação da educação superior no Brasil. A análise do anteprojeto de lei de educação superior, composto de cem artigos na versão de seis de dezembro de 2004, pode ser feita de diferentes formas. Apesar da sua extensão e da pertinência específica de grande número de capítulos e artigos que definem a abrangência da lei, a função social da educação superior e os objetivos a que ela deve atender, das normas para garantia de uma melhor regulação do setor privado stricto sensu, assim como da proposta do estatuto da autonomia, em seus diferentes aspectos constitucionais, e da subvinculação orçamentária para supostamente garantir, por meios jurídicos e sem menção as suas bases econômicas, a manutenção financeira das Instituições Federais de Educação Superior (IES), o anteprojeto apresenta uma série de limitações em sua formulação, que impedem uma resposta substancialmente positiva às questões acima expostas. 
Silva e Oliveira et al. (2006) investigaram o Plano Estratégico da Cidade de Juiz de Fora (MG), num esforço para detalhar seu processo de elaboração, suas características e as práticas de gestão capitaneadas por seu órgão executivo. Utilizaram entrevistas pessoais, observação não participante e análise documental. Através do Plano de Juiz de Fora (JF), a prefeitura ampliou sua capacidade de ação, apresentando uma alternativa à tradicional resposta "não há recursos". Ainda que o estímulo à participação social possa ser visto como estratégia de transferência de responsabilidades, a atuação solitária do poder local teria levado a um menor número de realizações. As particularidades de cada campo que condicionam a visão de mundo e a autonomia decisória de seus membros tornaram-se evidentes nos momentos de decisão, assim como a necessidade da mútua compreensão de interesses, possibilidades e limitações como pré-requisito para o diálogo.

Raschiatore e Moreira (2006) falam das inovações ocorridas na implementação do Programa Estadual de Microbacias Hidrográficas do Estado de São Paulo (PEMH). Discutem os conceitos de desenvolvimento sustentável, administração pública e programas e projetos de desenvolvimento. Esse Programa envolve 1.200 microbacias e 90.000 produtores rurais do Estado de São Paulo. O PEMH pode ser classificado como um programa complexo de desenvolvimento internacional, que a descentralização das ações é fator importante, assim como a mudança na forma de identificar, entender e atender às necessidades da comunidade, baseando-se na participação do público beneficiário. Também se pode identificar a importância de realizar uma ampla divulgação dos objetivos e dos resultados do programa. Os autores concluíram que, mesmo com a intenção de se criar uma estrutura própria e adequada ao PEMH, esta não foi totalmente possível e muitos problemas comuns foram apontados pelas avaliações realizadas pelo Banco Mundial em outros programas, podem ser confirmados nesse programa, como, por exemplo: a organização não estruturada para o gerenciamento de projetos; 0 contingenciamento orçamentário que gerou uma falta de recursos governamentais; os mecanismos de monitoração, acompanhamento e feedback inadequados; o fato de muitos riscos não identificados ou mesmo previstos, não terem sido tratados; burocracia (aprovações, aquisições, liberação de recursos, etc.); e escassez de recursos humanos.

Pode-se inferir, com base na evolução dos resultados alcançados pelo programa nos últimos anos, que a CATI conseguiu criar uma estrutura e uma capacitação tal, que esse programa seria bem mais efetivo se fosse iniciado nos dias de hoje. Toda a inovação e ferramental desenvolvido para a efetiva implementação do PEMH auxiliaram muito na sua evolução, e cabe destacar que o PEMH foi praticamente planejado nos primeiros anos de ação, em consequência de todas as necessidades, dificuldades e novidades que se apresentavam à instituição.

Garcia e Salles Filho (2009) analisam a evolução organizacional de um instituto público de pesquisa tecnológica, o Instituto de Tecnologia de Alimentos (ITAL), por meio de um estudo de caso, num período de 10 anos. Na sua trajetória institucional, o ITAL adotou uma organização descentralizada, o que Ihe permitiu aprofundar os laços com o setor produtivo e aumentar a participação das fontes extraorçamentárias no seu orçamento total. Como a 
ênfase é para a arrecadação junto ao setor produtivo, as unidades atendem, fundamentalmente, às demandas espontâneas, resultando em ausência de metas de médio e longo prazo, estabelecidas em conjunto com os setores produtivo e governamental e articuladas com as tendências globais, o que reforça a constatação de falta de visão de longo prazo. A política de trabalhar por demanda foi, com o tempo, acentuando as diferenças entre as unidades técnicas, que passaram a se especializar em tipos de serviços oferecidos. A descentralização proporcionou ao ITAL um melhor atendimento das demandas das empresas, nos diferentes ramos alimentícios, um aumento da capacidade de lidar com os diferentes graus de complexidade dos problemas colocados pelo setor produtivo e o aumento da capacidade de mobilizar o conhecimento para a solução de problemas. Concluiu-se, portanto, que a reorganização do ITAL em unidades técnicas descentralizadas trouxe-lhe vantagens inegáveis. Sua trajetória institucional aprofundou os laços com o setor produtivo e aumentou a participação das fontes extraorçamentárias no seu orçamento total.

O estudo realizado por Mello e Amâncio Filho (2010) relata a experiência da Fundação Oswaldo Cruz na perspectiva da mudança, fazendo uma abordagem crítica da gestão de recursos humanos em uma instituição pública de ciência e tecnologia em saúde, órgão de referência do Ministério da Saúde que ocupa posição estratégica no Sistema Único de Saúde e na formulação da Política Nacional de Ciência e Tecnologia em Saúde. Os resultados obtidos pelos autores possibilitaram observar a ausência de indicadores de recursos humanos, não permitindo avaliações objetivas de desempenho em relação às ações, metas e resultados previamente fixados para aferir, também, o desempenho institucional. Os autores ressaltam que para concretizar uma gestão de recursos humanos coerente com a modernização institucional exigida pelos requerimentos de excelência e qualidade dos serviços prestados ao cidadão, torna-se crucial instituir um sistema de incentivos atrelado a um processo de avaliação anual das atividades cumpridas bem como do potencial que cada profissional apresenta, podendo, inclusive, ser utilizadas técnicas empregadas no mercado de trabalho privado. Técnicas de promoção que valorizem a experiência profissional também podem ser aplicadas, como forma de reconhecer e de manter profissionais na instituição, em especial aqueles que, apesar de não possuírem titulação, são respeitados pelo notório saber em determinada área de conhecimento.

Com o processo de mudanças na administração pública do Estado de Minas Gerais iniciada em 2003 e com metas previstas até 2023. O principal objetivo de Queiroz e Ckagnazaroff (2010) foi verificar em que medida o modelo de gestão mineiro inovou tendo em vista duas perspectivas: a opinião dos atores envolvidos na construção, implementação e avaliação do choque de gestão (CG), e os preceitos teóricos da inovação no setor público. Dos resultados observados, os autores concluíram que o CG foi uma mudança de cunho estritamente gerencial, que inovou em termos estratégico, tecnológico, estrutural e de controle, não obtendo o mesmo êxito em relação às dimensões humana, cultural e política da mudança.

Lima e Vargas (2010) em seu estudo tinham por objetivo situar a discussão atual sobre inovação no setor público em revistas internacionais, em confronto com a teoria da inovação em serviços, visando identificar 
oportunidades de pesquisa. Os artigos revisados foram recuperados da base Science Direct referente ao período de 2006 a 2010. O exame dos artigos foi realizado com base em seis categorias de análise que serviram para revelar as abordagens adotadas pelos autores. Concluiu-se que os autores dos estudos da amostra têm interação restrita com a literatura de inovação em serviços. Os artigos revelam visão da inovação como mudança imposta de cima para baixo e não como processo interativo e essencial à atividade pública. São identificadas oportunidades de pesquisa mais detalhadas no nível organizacional e no nível micro, que reconheçam as especificidades do setor público.

O objetivo do artigo de Martins, Artmann e Rivera (2012) foi propor um modelo de gestão comunicativa de redes para o Sistema de Inovação em Saúde. Para isso discutiram sobre o complexo produtivo da saúde em sua relação com o desenvolvimento e apresentam algumas sugestões para 0 formato mais operacional da proposta. Utilizaram teóricos da linguagem, especialmente Habermas, e exemplos de outros países. Os autores chegaram à conclusão que apesar de algumas redes mais sistematizadas, o Brasil ainda não dispõe de um sistema nacional de inovação em saúde na sua plenitude. Vários autores analisados sustentam que a produção científico-tecnológica em saúde depende, em grande medida, do estabelecimento efetivo de redes, envolvendo uma interação complexa entre universidades, indústria e sistemas de assistência médica. O Estado teria um papel fundamental na regulação e coordenação do sistema de inovação.

Em 2013, Barbosa e Machado ao analisarem as características das estratégias de inovação adotadas pela Embrapa, sob a perspectiva da visão baseada em recursos (RBV), que tem potencial de gerar vantagem competitiva sustentável, observou que a empresa por contar com dezenas de unidades centrais e descentralizadas, estuda os mais diferentes produtos e atende a públicos distintos e que, embora muitas das tipologias de estratégia de inovação tenham sido identificadas na Embrapa, não necessariamente todas elas acontecem nas diversas unidades da empresa. Os autores concluíram que o recurso mais explorado pela Embrapa para sustentar suas estratégias de inovação consistiu no recurso humano, em especial, seus funcionários qualificados.

Brandão e Bruno-Faria (2013) tiveram por objetivo apresentar um panorama da produção científica em periódicos nacionais e internacionais sobre inovação no setor público no período entre 2000 e 2010. Foram analisados os objetivos dos estudos, as opções metodológicas assumidas pelos autores e as principais contribuições para o avanço da compreensão do tema. No Brasil, a produção em tais periódicos encontra-se em estágio inicial, mas se constata um número crescente de publicações nos últimos cinco anos. Já no contexto internacional, a produção científica encontra-se mais consolidada, em três principais focos de estudo: fatores ambientais, organizacionais e gerenciais que influenciam a inovação no setor público. Os autores identificaram lacunas de pesquisa em cinco temas: (a) processo de inovação, (b) indutores e barreiras, (c) características das lideranças que facilitam a inovação, (d) efeitos da inovação e (e) fatores que contribuem para a disseminação de inovações no setor público. 
A pesquisa de Freitas e Dacorso (2014) teve como objetivo analisar o Plano de Ação Brasileiro para o Governo Aberto, baseado na teoria da inovação aberta na gestão pública. Os autores utilizaram uma pesquisa documental e concluíram que os compromissos firmados pelo governo brasileiro estão consoantes com o processo de inovação aberta pública. As ações previstas no Plano estão especificamente relacionadas à transparência, abertura de dados, acesso à informação, e em alguns casos, participação da sociedade.

Em 2014, Brose fez uma revisão de periódicos das tendências da inovação na gestão pública subnacional desde a redemocratização. Concluiuse a necessidade de ampliação dos estudos nessa área. Devido à demanda por estudos quanto a novos serviços, procedimentos inovadores e modernização da gestão, o autor busca reforçar a necessidade de estudos sobre a qualidade da governança. $O$ autor evidencia o papel relevante da gestão pública na melhoria da qualidade de vida no Estado do Acre e sua preparação aos impactos das mudanças climáticas, com utilização da descrição da estratégia de desenvolvimento por meio do estudo de caso. A análise feita pelo autor permite refletir sobre a importância do contexto político e social do qual surgem inovações.

Ferreira et al. (2014) trata sobre inovação no setor público de saúde, com o objetivo de descrever e analisar o perfil das experiências que ganharam o Prêmio Inovação na Administração Pública Federal, entre 1995 e 2011. Os dados foram coletados no website da Escola Nacional de Administração Pública (ENAP). O autor analisou os dados de acordo com as dimensões: identificação dos casos, objetivos, tipo, abrangência e resultados do trabalho. Concluiu que os resultados apontam inovações incrementais, com predominância do tipo de inovação de processo e serviços, com foco na busca de eficiência operacional, e tiveram abrangência nacional.

Pimentel, Figueiredo-Silva (2014) fizeram uma análise dos principais direitos de propriedade intelectual de software e de padrões de software, apontando diferenças entre o proprietário e o livre, fazendo referência às políticas públicas de inovação no Brasil. Os autores trouxeram uma revisão conceitual das principais características e dos efeitos jurídicos da opção pela utilização de software e padrão proprietários, software e padrão livre. A utilização de software proprietário ou livre não é excludente, nem se pode obrigar por lei o setor público ou privado a optar por um ou por outro. Do ponto de vista dos governos, a escolha de produtos e serviços deverá ser feita caso por caso, facilitando o maior nível de competência e concorrência possível entre os fornecedores. Os governos podem estimular o desenvolvimento de novas soluções tecnológicas.

\subsection{Síntese das Discussões sobre Inovação no Setor Público (2000-2014)}

No Quadro 4 apresenta-se uma síntese com uma classificação por assuntos referente ao tema inovação no setor público. Categorizou-se em nove temas. 


\section{Quadro 4: Síntese das discussões da inovação no setor público.}

\begin{tabular}{|l|c|l|}
\hline \multicolumn{1}{|c|}{ Assunto/Tema } & Quantidade & \multicolumn{1}{|c|}{ Autores } \\
\hline (1) Inovação em saúde pública & 5 & $\begin{array}{l}\text { Costa et.al (2000); Gerschaman (2001); } \\
\text { Mello e Amâncio Filho (2010); Martins, } \\
\text { Artmann e Rivera (2012); Ferreira et.al. } \\
\text { (2014). }\end{array}$ \\
\hline $\begin{array}{l}\text { (2) Inovação na gestão pública } \\
\text { federal }\end{array}$ & 2 & $\begin{array}{l}\text { Barbosa e Machado (2013); Freitas e } \\
\text { Dacorso (2014). }\end{array}$ \\
\hline $\begin{array}{l}\text { (3) Inovação nas gestões públicas } \\
\text { estaduais }\end{array}$ & 4 & $\begin{array}{l}\text { Quadros et.al. (2000); Raschiatore e } \\
\text { Moreira (2006); Queiroz e Ckagnazaroff } \\
\text { (2010); Brose (2014). }\end{array}$ \\
\hline $\begin{array}{l}\text { (4) Inovação nas gestões públicas } \\
\text { municipais }\end{array}$ & 2 & $\begin{array}{l}\text { Baracchini (2002); Silva e Oliveira et. al. } \\
\text { (2006). }\end{array}$ \\
\hline $\begin{array}{l}\text { (5) Discussão entre inovação e } \\
\text { melhores práticas }\end{array}$ & 1 & Spink (2003). \\
\hline (6) Inovação na educação & 1 & Silva Júnior e Sguissardi (2005). \\
\hline $\begin{array}{l}\text { (7) Inovação em pesquisa e em propriedade } \\
\text { tecnologia }\end{array}$ & 1 & Garcia e Salles Filho (2009). \\
\hline $\begin{array}{l}\text { (8) Inovação em } \\
\text { intelectual e políticas públicas }\end{array}$ & 3 & $\begin{array}{l}\text { Conde e Araújo-Jorge (2003); Lima e } \\
\text { Vargas (2010); Brandão e Bruno-Faria } \\
\text { (2013). }\end{array}$ \\
\hline $\begin{array}{l}\text { (9) Estudos bibliométricos } \\
\text { Total }\end{array}$ & 20 & \\
\hline
\end{tabular}

Fonte: Elaboração própria.

Ao tecer um comparativo entre as publicações analisadas é possível constatar que a saúde é uma tendência quando se trata de inovação no setor público (1). Costa et al. (2000) examinou as principais inovações gerenciais, identificando tendências de desenvolvimento e sugerindo rotinas de avaliações, tomando como caso a área da saúde nas regiões metropolitanas de São Paulo. Gerschaman (2001) avaliou o que as inovações gerenciais produziram no setor da saúde no processo de descentralização da política de saúde. Martins, Artmann e Rivera (2012) pesquisaram um modelo de gestão comunicativa de redes para o SUS (Sistema Único de Saúde) com objetivo de agilizar a comunicação e circulação entre os componentes do sistema. Ferreira et.al (2014) analisam o perfil das experiências que ganharam o Prêmio Inovação na Administração Pública Federal, sugerindo incentivos governamentais para a inovação na saúde do setor público. Mello e Amâncio Filho (2010) relatam a experiência da Fundação Oswaldo Cruz na perspectiva da mudança do padrão de acumulação capitalista por formas produtivas flexibilizadas e desregulamentadas.

As discussões sobre a inovação na gestão federal (2) abrangem o estudo de Barbosa e Machado (2013) que analisaram as características das estratégias de inovação adotadas pela Embrapa, com foco no recurso humano, 
em especial, seus funcionários qualificados. Freitas e Dacorso (2014), baseados na teoria da inovação aberta na gestão pública, analisaram o Plano de Ação Brasileiro para o Governo Aberto.

Quanto à inovação nas gestões estaduais (3), Quadros et al. (2000) abordaram sobre o sistema de inovação paulista à luz da análise das informações sobre o sistema público de C\&T (Ciência e Tecnologia) no Estado de São Paulo. Os autores Raschiatore e Moreira (2006) discorreram das inovações ocorridas na implementação do Programa Estadual de Microbacias Hidrográficas do Estado de São Paulo - PEMH. Queiroz e Ckagnazaroff (2010) verificaram em que medida o modelo de gestão mineiro inovou com o processo de mudanças na administração pública do Estado de Minas Gerais iniciada em 2003 e com metas previstas até 2023. Brose (2014) abordou sobre as tendências de inovação na gestão pública tendo como estudo de caso o Estado do Acre.

Sobre inovação nas gestões municipais (4), Baracchini (2002) cita que os programas inovadores promovidos por governos municipais são parte das alterações do estado e também nos processos de formulação e implementação das políticas públicas. Silva e Oliveira et. al. (2006) investigaram o Plano Estratégico da Cidade de Juiz de Fora (MG), num esforço para detalhar seu processo de elaboração, suas características e as práticas de gestão capitaneadas por seu órgão executivo.

Spink (2003) utilizando o Programa Gestão Pública e Cidadania criado em 1996, fala sobre o tema inovação a partir de respostas dos programas, projetos e atividades identificadas a esta questão, trazendo uma nova ótica à discussão entre inovação e melhores práticas (5).

A inovação na educação (6) é representada apenas por um estudo, o de Silva Júnior e Sguissardi (2005) que expõem alguns elementos históricos, conceituais e de princípios, para um exame preliminar do anteprojeto de lei da educação superior, na versão de 2004, como parte e decorrência do processo de transformação da educação superior no Brasil.

Como inovação em pesquisa e tecnologia (7), Garcia e Salles Filho (2009) analisaram a evolução organizacional de um instituto público de pesquisa tecnológica, o Instituto de Tecnologia de Alimentos (ITAL) por meio de um estudo de caso, num período de 10 anos.

Pimentel e Figueiredo-Silva (2014) fazendo referência às políticas públicas de inovação no Brasil fizeram uma análise dos principais direitos de propriedade intelectual (8) de software e de padrões de software.

Houve três estudos bibliométricos (9) ou levantamento da literatura. Conde e Araújo-Jorge (2003) fizeram uma revisão na literatura com o termo inovação. Lima e Vargas (2010) verificam a discussão sobre inovação no setor público no Brasil nos periódicos de 2006 a 2010. Brandão e Bruno-Faria (2013) vão um pouco mais além e pesquisaram os periódicos nacionais e internacionais no período de 2000 a 2010. 


\section{CONSIDERAÇÕES FINAIS}

O objetivo da pesquisa foi fazer o levantamento das discussões do tema inovação no setor público brasileiro após a vigência da LRF, ou seja, desde o ano 2000, até 2014. O estudo revelou que as publicações de artigos relacionados ao tema após a promulgação dessa norma fiscal passou a ter mais destaque em 2014.

No estudo de Lima e Vargas (2010) foi verificado a discussão sobre inovação no setor público no Brasil, e esses autores concluíram que a literatura nacional sobre inovação apresentou interação restrita entre si e com estudos sobre inovação em serviços. Ao se fazer um comparativo dos resultados desses autores com os do presente estudo pode-se dizer que 0 aprofundamento deste foi maior, pois na base de dados Scielo a busca retornou 20 periódicos em um período mais abrangente (2000 a 2014), sendo que cinco artigos são de publicação em 2014, mostrando o que de mais recente tem sido discutido sobre inovação no setor público. Embora o período analisado fosse de 14 anos, pode-se dizer que há pouca discussão sobre este tema na base de dados consultada.

Verifica-se que a discussão sobre inovação no setor público é atual e predomina as discussões sobre a saúde pública, seguida do tema inovações no âmbito da gestão estadual. Percebeu-se, no entanto, o pouco interesse em estudos sobre inovação pública com foco na educação pública.

Como limitação do estudo cita-se o fato de se ter usado para pesquisa apenas a base Scielo, e em artigos da língua portuguesa. Como sugestão de futuras pesquisas, expandir a consulta a outras bases de dados como Periódicos da CAPES, Scientific Periodicals Electronic Library (Spell) e Web of Science bem como em eventos importantes sobre Administração Pública e com pesquisas na literatura estrangeira para efeito de comparação ou ampliar as análises das discussões.

\section{REFERÊNCIAS}

ANDRADE JÚNIOR, P. P.; CERANTO, F. A. A. Um retrato bibliométrico da produção cientifica brasileira sobre Gestão da Tecnologia e da Inovação no período 2001-2011. Revista de Administração da Universidade Federal de Santa Maria, v. 6, n .6, p. 708-719, 2013.

BARACCHINI, S. A. A inovação presente na administração pública Brasileira. Revista de Administração de Empresas, v. 42, n. 2, p. 104-109, abr./jun., 2002.

BARBOSA, R; MACHADO, A. Estratégia de inovação sob a perspectiva da visão baseada em recursos: Um estudo na Embrapa. Gestão \& Regionalidade, v. 29, n. 87, set./dez., 2013.

BAUTZER, D. Inovação: repensando as organizações. São Paulo: Atlas, 2009. 
BRANDÃO S. M; BRUNO-FARIA M. F. Inovação no setor público: análise da produção científica em periódicos nacionais e internacionais da área de administração. Revista de Administração Pública, v. 47, n. 1, p. 227-248, jan./fev., 2013.

BRESSER PEREIRA, L. C. A Reforma Gerencial do Estado de 1995. Revista de Administração Pública, Rio de Janeiro, v. 34, n.4, p.7-26, jul./ago., 2000.

BROSE, M. E. Inovação na gestão pública subnacional: reflexões sobre a estratégia de desenvolvimento do Acre. Revista de Administração Pública, v. 48, n. 2, p. 277-294 mar./abr., 2014.

BÜTTENBENDER, P. et al. Gestão da Inovação, performance e agregação de valor: um estudo de caso da cadeia do agronegócio. Rio de Janeiro, Vis. futuro [online], v.12, n.2, 2007.

CAMPELO, M. Contribuição ao estudo de um modelo conceitual de excelência em gestão pública. In: MACHADO, N. et al. GBRSP - Gestão baseada em resultado no setor público: uma abordagem para implementação em prefeituras, câmaras municipais, autarquias, fundações e unidades organizacionais. São Paulo: Atlas, 2012.

CONDE, M. V. F.; ARAÚJO-JORGE, T. C. Modelos e concepções de inovação: a transição de paradigmas, a reforma da C\&T brasileira e as concepções de gestores de uma instituição pública de pesquisa em saúde. Ciência \& Saúde Coletiva, v. 8, n. 3, p. 727-741, 2003.

COSTA N. R. et.al. Reforma do Estado e mudança organizacional: um estudo de hospitais públicos. Ciência \& Saúde Coletiva, v. 5, n. 2, p. 427442, 2000.

DAFT, R. L. Organizações: teoria e projetos. Tradução: Ez2 Translate. 11. ed. São Paulo: Cengage Learning, 2014.

DIAS, R. Eco Inovação: Caminho para o crescimento sustentável. São Paulo: Atlas, 2014.

FERREIRA V. R. S. et al. Inovação em serviços de saúde no Brasil: análise dos casos premiados no Concurso de Inovação na Administração Pública Federal. Revista de Administração Pública, v. 48, n. 5, p. 1207-1227, set./out., 2014.

FREITAS, R. K.V.; DACORSO, A. L. R. Inovação aberta na gestão pública: análise do plano de ação brasileiro para a Open Government Partnership. Revista de Administração Pública, v.48, n.4, p.869-888, jul./ago. 2014.

GARCIA, A. E. B; SALLES FILHO, S. L. M. Trajetória institucional de um instituto público de pesquisa: o caso de Ital após 1995. Revista de Administração Pública, v.3, p.661-93, mai./jun. 2009.

GERSCHMAN, S. Municipalização e inovação gerencial. Um balanço de década de 1990. Ciência \& Saúde Coletiva, v. 6, n. 2, p. 417-434, 2001. 
GIL, A. C. Métodos e técnicas de pesquisa social. 6. ed. São Paulo: Atlas, 2008.

GIRARDELLO, M.; MAIA, O. Os desafios da infraestrutura e o papel inovador do governo. In: DUBOIS, R.; LINS, J. (Coords.). Inovação na gestão pública. São Paulo: Saint Paul Editora, 2012.

LIMA, D. H.; VARGAS, E. R. O Estado da Arte sobre Inovação no Setor Público: Como Estudos de Inovação em Serviços Podem Contribuir? XXXIV Encontro da Associação Nacional de Pós-graduação e Pesquisa em Administração. Anais... Rio de Janeiro, ANPAD, set. 2010.

Estudos internacionais sobre inovação no setor público: como a teoria da inovação em serviços pode contribuir? Revista de Administração Pública, v. 2, p. 385-401, mar./abr., 2012.

MARTINS, W. J.; ARTMANN, E.; RIVERA, F. J. U. Gestão comunicativa para redes cooperativas de ciência, tecnologia e inovação em saúde. Revista Saúde Pública, v. 46 (Supl): p.51-8, 2012.

MATIAS-PEREIRA, J. Manual de gestão pública contemporânea. São Paulo: Atlas, 2008.

MELLO M.L.B. C.; AMANCIO FILHO A. A gestão de recursos humanos em uma instituição pública brasileira de ciência e tecnologia em saúde: 0 caso Fiocruz. Revista de Administração pública, v.3, p. 613-36, maio/jun. 2010.

OLIVEIRA, R. Gestão pública: democracia e eficiência. Rio de Janeiro: FGV, 2012.

PASCARELLI FILHO, M. A nova administração pública: profissionalização, eficiência e governança. São Paulo: DVS Editora, 2011.

PIMENTEL, L.O; FIGUEIREDO-SILVA, C. E. R. Conceito Jurídico de Software, Padrão Proprietário e Livre: Políticas Públicas. Revista Sequência, Florianópolis, n. 68, p. 291-329, jun., 2014.

QUADROS R. et al. Força e fragilidade do sistema de inovação paulista. São Paulo em Perspectiva, São Paulo, v. 14, n. 3, p. 124-141, 2000.

QUEIROZ, R. G. M.; CKAGNAZAROFF, I. B. Inovação no setor público: uma análise do choque de gestão (2003-10) sob a ótica dos servidores e dos preceitos teóricos relacionados à inovação no setor público. Revista de Administração Pública, v.3 p. 679-705, mai./jun. 2010.

RASCHIATORE R. A.; MOREIRA D. A. Inovações na Implementação do Programa Estadual de Microbacias Hidrográficas do Estado de São Paulo. Gestão e Produção, v.13, n.3, p. 517-529, set./dez., 2006.

RIBEIRO, J. C. de M.; FARIAS, R. A. Inovação no setor público. In: MACHADO, N. et al. GBRSP - Gestão baseada em resultado no setor público: uma abordagem para implementação em prefeituras, câmaras municipais, autarquias, fundações e unidades organizacionais. São Paulo: Atlas, 2012. 
SILVA E OLIVEIRA V. C. et. al. Inovação gerencial em municípios: análise exploratória das práticas de gestão do Plano Estratégico de Juiz de Fora. Cadernos EBAPE.BR, v. 4, n. 4, dez., 2006.

SILVA JÚNIOR, J. R.; SGUISSARDI, V. A nova lei de educação superior: fortalecimento do setor público e regulação do privado/mercantil ou continuidade da privatização e mercantilização do público? Revista Brasileira de Educação, n. 29, mai./ago, 2005.

SILVA, F. M.; MELLO, S. P. T.; TORRES, I. A. C. O que se discute sobre gestão por competências no setor público: um estudo preliminar das construções. Revista de Administração UFSM, v. 6, n. 4, p. 685-693. dez., 2013.

SPINK, P. Inovação na perspectiva dos inovadores: a experiência do Programa Gestão Pública e Cidadania. Cadernos EBAPE.BR, v.1, n. 2, 2003.

TIDD, J.; BESSANT, J.; PAVITT K. Gestão da inovação. Tradução: Elizamari Rodrigues Becker. 3. ed. Porto Alegre: Bookman, 2008.

ZANI, F; SPINELLI, R. Inovação na gestão pública: eficiência com participação. Rio de Janeiro, 2010.

Submetido em: $14 / 06 / 15$

Aceito em: $27 / 11 / 15$ 